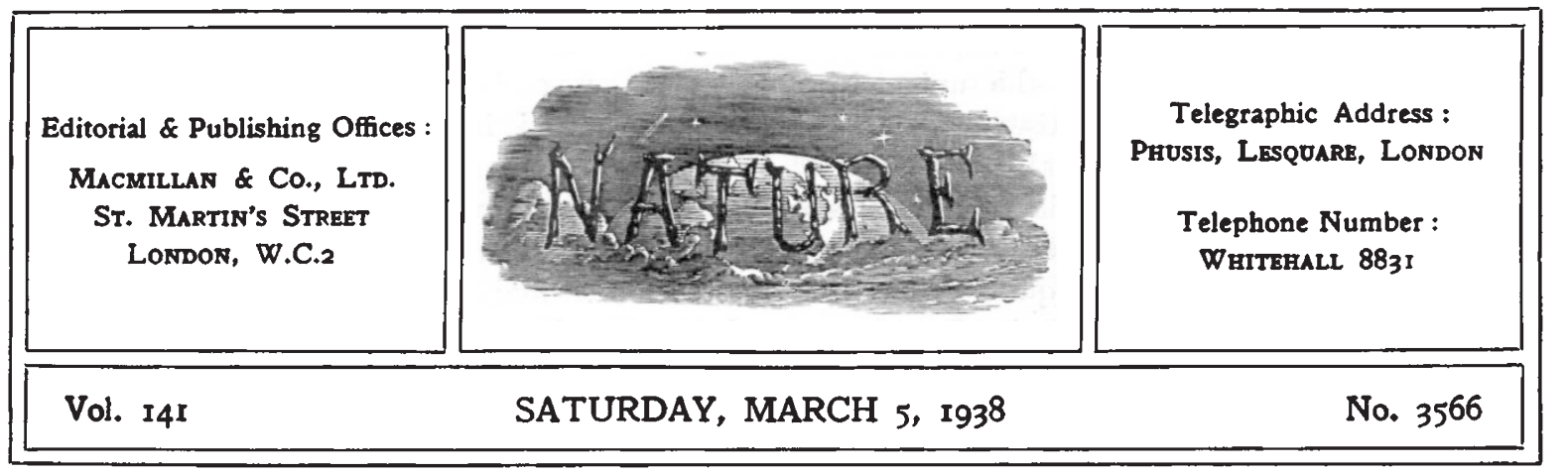

\title{
The Shifting Focus of Science
}

$\mathrm{T}$ HE shifting focus of scientific interest has received scant attention either from historians or from men of science. The temptation always is to study the changing scene in terms of its great figures, to believe, in atomistic fashion, that each problem is born of the personal intellectual interest of the individual man of science ; that it has been brought to the notice of his contemporaries by a pure but inexplicable effort of imagination. While it is true that creative thinking of an individual nature must play its part in the making of science, it is equally obvious that the movement in interest cannot possibly be wholly accounted for, on this basis. The problems of Faraday and Maxwell were beyond the imagina. tion of Newton, and those of the modern period outside the mental scope of all three. This does not mean that Faraday and Maxwell were greater figures than Newton, but rather that no man of science can do other than concern himself with the problems characteristic of his period.

The changing face of science can be seen without difficulty to fall into clearly defined stages. We have just suggested three. Each phase is carried through by the activity of the individual scientific workers, great and small, contributing in various measures, partly driven on by the developing internal logic of the subject and its accumulating experimental knowledge, partly canalized and fed by outside social forces not normally apparent to the individual workers. How scientific work is financed, and for what social purpose that work is pursued, for example, is a question the answer to which, in these days of industrial and govern. mental research, points to one only of the socially determining factors. The shifting focus of science, however much it may provide subjective satisfaction to its devotees, is nevertheless an objective feature of Nature, and therefore, if for that reason alone, a fit subject for scientific investigation.

To-day we are witnessing just such a shift. It began tentatively in the early days of this century with a scrutiny of the logic of mathematics and a study of the methodology of science. It passed to a series of startling attempts to evaluate the philosophical implications of more recent scientific knowledge, implications that sought to deny the certainty of science and strove to lead it back into mysticism. The significant feature of this phase was that these pronouncements were couched in popularized writings, a concession to a sense of social responsibility. Now at last a serious attempt is being made to probe further back to the social origins and social consequences of scientific discovery. The alertness shown in the columns of Nature to the social possibilities of science, to its destructive as well as its constructive features, to the travesties of truth that are used to bolster up national doctrines, and generally to the distortion and prostitution of science to ignoble ends, is itself a significant feature of this same analysis. Scientific history, like ordinary history, is at last beginning to be seen in its social context; and the shifting focus of science is part of its history.

The new concern of men of science with the uses and misuses of science has undoubtedly developed with the increasing tenseness of the international situation. The concern of this journal with these matters evidently derives from this source, but did not in fact become apparent until the latter had reached a critical stage. Nevertheless, the social background was always there for study. It required a social crisis to direct our attention to it. 
Every shift in interest of science is accompanied by opposition on the part of those absorbed in the older problems and convinced that the new development leads away from the true path of scientific rectitude. A multitude of specious reasons are certain to be brought forward to show that political prejudice must necessarily intervene to prevent the formation of balanced judgments. Such considerations need not deter those who are genuinely concerned with the trend of scientific development as a feature of natural change.

The personal motives that urge individuals rather than the group to concentrate on such questions when the time is socially ripe for their study are many. In "Mathematics for the Million"*, for example, the author is apparently induced to do so in order to take the mystery out of mathematics, and to open the door to an understanding of its meaning for the ordinary citizen. How mathematics could be anything but a mystery to those who have not perceived its social sources is itself a mystery. In this respect, it is sufficient of a miracle to many scientific workers. To mathematicians who do not see it as one of the forms of social energy, it can have but a restricted meaning. In his own way, Hogben has established beyond dispute the existence of a qualitative relation between the growth of mathematical facts and the severely practical problems of the society that gave them birth. That is in itself a significant scientific advance. What requires further elucidation is the changing nature of this relationship.

- Mathematics for the Million. A Popular Self-Educator. By Lancelot Hogben. Revised second edition. Pp. 658. (London: Allen and Unwin, Ltd.) 128. Bd. net.
In its early history, society encountered quite definite immediate problems that required for their solution a definite mathematical technique. By the eighteenth century, the situation in this respect had become drastically transformed. The new merchant and industrial aristocracy was pur. chasing social prestige by the endowment of university foundations, and educational institutions generally. While out of the practical needs of social life there had blossomed forth the earlier mathematics that dealt with the directly important problems of mensuration, experimental practice had also been called into being for these same ends : and experimental practice involves theory, and theory its mathematical technique, and mathematical technique its special tools and its specific logical problems. To such questions could the universities devote themselves, but the linkage with the severely practical problems of social life, the problems of the common man, while it still existed, had become more remote. The danger for us lies in the belief that that link no longer exists, a belief that shows itself in the idea that mathematics is an independent logical discipline with an absolute line of cleavage between its pure and its applied form. It shows itself in the effort to accord to mathematical ideas a priority over the physical facts of the world and so to present the universe and the struggling society on this earth as a series of grandiose mathematical theorems. Hogben's book is not a mathematical text-book except in a very popular sense-in itself a very important sense--but if its publication should serve to direct attention to the social linkages between the sciences, it will have performed a very significant service.

H. L.

\section{The End of the Road}

A Comprehensive Treatise on Irorganic and Theoretical Chemistry

By Dr. J. W. Mellor. Vol. 16 : Pt. and General Index. Pp. $x+811$. (London, New York and Toronto: Longmans, Green and Co., Ltd., 1937.) 63s. net.

$\mathrm{T}$ $\mathrm{HE}$ road of inorganic chemical knowledge is paved with bricks, of silver and sodium, lithium and lead, platinum and phosphorus, helium and uranium, representing all the elements which Mendeléeff provided for and more besides, as well as their numerous compounds; it is sur- faced with what road experts call a binder, but which we, the initiated, designate as 'Mellor's magic', a highly original and individual variety. Slowly the magic has prevailed, as good magic always must when diligently applied, and so at last the end of the road has been reached-index and all. Riders in quest of knowledge can traverse it from end to end: it has been well and truly printed.

In more prosaic language, Mellor's "Comprehensive Treatise" is completed: in fifteen years, the vast field of inorganic chemistry has been surveyed. Such an achievement ought to be a 